\title{
ACCELERATED LIFE TESTING WITH AN UNDERLYING THREE-PARAMETER WEIBULL MODEL
}

Daniel I. De Souza Jr' Kamalesh Somani ${ }^{2}$.

\begin{abstract}
The main objective of life testing is to obtain information concerning failure. This information should then be used in order to quantify reliability, improve product reliability, and to determine whether safety and reliability goals are being met. The amount of time available for testing directly at use conditions, that is, with practical test times and realistic (relatively) small test sample sizes, could be considerably less than the component's expected lifetime. To overcome such a problem, there is the life-testing alternative aimed at forcing components to fail by testing them at much higher than the intended application conditions. By doing this, we will get failure data that can be fitted to life distribution models. To go from the failure rate obtained at high stress to what a product or service is likely to experience at much lower stress, under use conditions, we will need additional modeling. These models are known as acceleration models. The accelerated life testing concept is such that a component, operating under predetermined (correct) levels of increased stress, will have exactly the same failure mechanism as observed when used at normal stress levels. For example, if the time of testing is measured in cycles, then the time squeezing may only require increasing the number of cycles per unit of time. In this study, we will develop an accelerated life-testing model in which the underlying sampling distribution is the three-parameter Weibull model. We will be assuming a linear acceleration condition. An example will illustrate the application of the proposed accelerated life-testing model.
\end{abstract}

Keywords: Accelerated Life Testing; Three-Parameter Weibull Model; Linear Acceleration; Maximum Likelihood Mechanism.

\footnotetext{
${ }^{1}$ Uni. Fed. Fluminense, Dept. de Eng Civil e Uni. Est. do Norte Fluminense, Lab. Eng. de Produção. Brazil

${ }^{2}$ University of Florida, Industrial and Systems Engineering Department. Gainesville, FL, USA.

ENGEVISTA, v. 7, n. 1, p. 55-62, abril 2005
} 


\section{INTRODUCTION}

The accelerated life testing concept is such that a component, operating under predetermined (correct) levels of increased stress, will have exactly the same failure mechanism as observed when used at normal stress levels. Failures will happen more quickly, no new failure modes are introduced. So, if the life distribution for units operating at a high laboratory stress is known, and if the appropriate time scale transformation to lower stress conditions is known, then it will be possible to mathematically derive the life distribution at lower stress. The simplest model assumes a constant (linear) acceleration effect over time. Therefore, if we define the linear acceleration factor by AF, we will have:

$$
\mathrm{t}_{\mathrm{n}}=\mathrm{AF} \times \mathrm{t}_{\mathrm{a}}
$$

Here, $t_{n}$ is the time to failure under normal (standard) stress, and $t_{a}$ is the time to failure at high stress level.

The cumulative distribution function at normal testing condition $F_{n}\left(t_{n}\right)$ for a certain testing time $t=t_{n}$ will be given by:

$$
\begin{aligned}
& \mathrm{P}\left(\mathrm{T}_{\mathrm{n}}<\mathrm{t}_{\mathrm{n}}\right)=\mathrm{F}_{\mathrm{n}}\left(\mathrm{t}_{\mathrm{n}}\right)=\mathrm{P}\left(\mathrm{T}_{\mathrm{a}}<\mathrm{t}_{\mathrm{a}}\right)= \\
& =\mathrm{F}_{\mathrm{a}}\left(\frac{\mathrm{t}_{\mathrm{n}}}{\mathrm{AF}}\right) \\
& \quad \mathrm{F}_{\mathrm{n}}\left(\mathrm{t}_{\mathrm{n}}\right)=\mathrm{F}_{\mathrm{a}}\left(\frac{\mathrm{t}_{\mathrm{n}}}{\mathrm{AF}}\right)
\end{aligned}
$$

The density function at normal testing condition $\mathrm{f}_{\mathrm{n}}(\mathrm{t})$ for a certain testing time $t$ will be given by:

$$
\mathrm{f}_{\mathrm{n}}(\mathrm{t})=\frac{\mathrm{d}}{\mathrm{dt}} \mathrm{F}_{\mathrm{a}}\left(\frac{\mathrm{t}}{\mathrm{AF}}\right)=\frac{1}{\mathrm{FA}} \mathrm{f}_{\mathrm{a}}\left(\frac{\mathrm{t}}{\mathrm{AF}}\right)
$$

The hazard rate at normal testing condition $\mathrm{h}_{\mathrm{n}}(\mathrm{t})$ for a certain testing time $t$ will be given by:

$$
\begin{aligned}
& h_{n}(t)=\frac{f_{n}(t)}{R_{n}(t)}=\frac{\frac{1}{A F} f_{a}\left(\frac{t}{A F}\right)}{1-F_{a}\left(\frac{t}{A F}\right)} \\
& h_{n}(t)=\frac{1}{A F} h_{a}\left(\frac{t}{A F}\right)
\end{aligned}
$$

\section{THREE-PARAMETER WEIBULL DISTRIBUTION ACCELERATION}

Sequential life testing approach with a two-parameter Weibull underlying sampling distribution was analyzed before by De Souza [1], [2], [3], [4], Sequential life testing approach with a three-parameter Weibull underlying sampling model was also addressed by De Souza [5], [6].

An accelerated life testing approach in which the underlying sampling distribution is the two-parameter Weibull model was addressed before by De Souza [7], [8]. The two-parameter Weibull distribution was addressed before by Erto [9], Mann [10], Papadopoulos and Tsokos [11], Soland [12] and Tate [13]. In this work, we will develop an accelerated life testing approach in which the underlying sampling distribution is the three-parameter Weibull model. We will be assuming that the location parameter or minimum life is different from zero.

So, let us define the following parameters of the sampling Weibull distribution: $\beta_{\mathrm{n}}=$ shape parameter under normal testing conditions; $\beta_{\mathrm{a}}=$ shape parameter under accelerated testing conditions; $\theta_{\mathrm{n}}$ $=$ scale parameter under normal testing conditions; $\theta_{\mathrm{a}}=$ scale parameter under accelerated testing conditions; $\varphi_{\mathrm{n}}=$ minimum life under normal testing conditions; $\varphi_{\mathrm{a}}=$ minimum life under accelerated testing conditions. Then the cumulative distribution function at accelerated condition $F_{a}(t)$ of the threeparameter Weibull distribution will be given by: 


$$
\mathrm{F}_{\mathrm{a}}(\mathrm{t})=1-\exp \left[-\left(\frac{\mathrm{t}-\varphi_{\mathrm{a}}}{\theta_{\mathrm{a}}}\right)^{\beta_{\mathrm{a}}}\right]
$$

In general, the scale parameter and the minimum life can be estimated at two different stress levels (temperature, cycles, miles, etc.), and their ratios will provide the desired value for the acceleration factor $\mathrm{AF}_{\theta}$ and $\mathrm{AF}_{\varphi}$. So, we will have:

$$
\mathrm{AF}_{\theta}=\frac{\theta_{\mathrm{n}}}{\theta_{\mathrm{a}}}
$$

Or also:

$$
\mathrm{AF}_{\varphi}=\frac{\varphi_{\mathrm{n}}}{\varphi_{\mathrm{a}}}
$$

Also, $\mathrm{AF}_{\theta}=\mathrm{AF}_{\varphi}=\mathrm{AF}$.

Using now equation (2), we obtain the cumulative distribution function at normal testing condition $F_{n}\left(t_{n}\right)$ for a certain testing time $t=t_{n}$, we will have

$$
\begin{aligned}
F_{n}(t)= & F_{a}\left(\frac{t}{A F}\right)= \\
& =1-\exp \left[-\left(\frac{t-\varphi_{a}}{\theta_{a} A F}\right)^{\beta_{a}}\right]
\end{aligned}
$$

From equation (7), we have $\varphi_{\mathrm{a}}=\varphi_{\mathrm{n}} / \mathrm{AF}$. Then, we obtain

$$
\begin{aligned}
& F_{n}(t)=F_{a}\left(\frac{t}{A F}\right) \\
& F_{n}(t)=1-\exp \left[-\left(\frac{t-\frac{\varphi_{n}}{A F}}{\theta_{a} A F}\right)^{\beta_{a}}\right]
\end{aligned}
$$

Since $\theta_{\mathrm{a}} \mathrm{AF}=\theta_{\mathrm{n}}$ and $\beta_{\mathrm{a}}=\beta_{\mathrm{n}}=\beta$, equation (8) becomes:

$$
\mathrm{F}_{\mathrm{n}}(\mathrm{t})=1-\exp \left[-\left(\frac{\mathrm{t}-\frac{\varphi_{\mathrm{n}}}{\mathrm{AF}}}{\theta_{\mathrm{n}}}\right)^{\beta_{\mathrm{n}}}\right]
$$

Equation (9) tells us that, under a linear acceleration assumption, if the life distribution at one stress level is represented by a three-parameter Weibull model, the life distribution at any other stress level is also represented by a threeparameter Weibull model. The shape parameter remains the same while the accelerated scale parameter and the accelerated minimum life parameter are multiplied by the acceleration factor. The equal shape parameter is a necessary mathematical consequence to the other two assumptions; assuming a linear acceleration model and a three-parameter Weibull sampling distribution. If different stress levels yield data with very different shape parameters, then either the three-parameter Weibull sampling distribution is the wrong model for the data or we do not have a linear acceleration condition.

The hazard rate of a three-parameter Weibull sampling distribution varies under acceleration. For a stress failure rate the hazard function $h_{a}(t)$ will be given by:

$$
\mathrm{h}_{\mathrm{a}}(\mathrm{t})=\frac{\beta}{\theta_{\mathrm{a}}}\left(\frac{\mathrm{t}-\varphi_{\mathrm{a}}}{\theta_{\mathrm{a}}}\right)^{\beta-1}
$$

Again, from equation (7) we have that $\varphi_{\mathrm{a}}=\varphi_{\mathrm{n}} / \mathrm{AF}$. Then, we obtain

$$
\mathrm{h}_{\mathrm{a}}(\mathrm{t})=\frac{\beta}{\theta_{\mathrm{a}}}\left(\frac{\mathrm{t}-\frac{\varphi_{\mathrm{n}}}{\mathrm{AF}}}{\theta_{\mathrm{a}}}\right)^{\beta-1}
$$

As we remember, $\theta_{\mathrm{n}}=\theta_{\mathrm{a}}$ AF. Then, when we multiply equation (10), the hazard rate at accelerated testing condition $\mathrm{h}_{\mathrm{a}}(\mathrm{t})$, by the factor $1 /(\mathrm{AF})^{\beta}$, we will have as a result the hazard rate at normal testing condition $h_{n}(t)$. Then, we will have: 


$$
\begin{gathered}
\mathrm{h}_{\mathrm{n}}(\mathrm{t})=\frac{\beta}{\theta_{\mathrm{a}} \mathrm{AF}}\left(\frac{\mathrm{t}-\frac{\varphi_{\mathrm{n}}}{\mathrm{AF}}}{\theta_{\mathrm{a}} \mathrm{AF}}\right)^{\beta-1}, \quad \text { or yet: } \\
\mathrm{h}_{\mathrm{n}}(\mathrm{t})=\frac{1}{(\mathrm{AF})^{\beta}} \frac{\beta}{\theta_{\mathrm{a}}}\left(\frac{\mathrm{t}-\frac{\varphi_{\mathrm{n}}}{\mathrm{AF}}}{\theta_{\mathrm{a}}}\right)^{\beta-1} \text {. Then: } \\
\mathrm{h}_{\mathrm{n}}(\mathrm{t})=\frac{\mathrm{h}_{\mathrm{a}}(\mathrm{t})}{(\mathrm{AF})^{\beta}}
\end{gathered}
$$

There was a linear change in the hazard rate at acceleration testing condition $h_{a}(t)$. When $h_{a}(t)$ is multiplied by the factor $1 /(\mathrm{AF})^{\beta}$, we will have as a result the hazard rate at normal testing condition $\mathrm{h}_{\mathrm{n}}(\mathrm{t})$. Only when the sampling population is exponential (the shape parameter $\beta$ is equal to 1 ), will the multiplication factor be equal to $1 / \mathrm{AF}$.

\section{DETERMINING AN INITIAL} ESTIMATE TO THE MINIMUM LIFE PARAMETER $\varphi$

The $p d f$ of $\mathrm{t}_{1}$, the first failure time, will be given by

$$
\begin{aligned}
& \mathrm{f}\left(\mathrm{t}_{1}\right)=\mathrm{n}\left[1-\mathrm{F}\left(\mathrm{t}_{1}\right)\right]^{\mathrm{n}-1} \mathrm{f}\left(\mathrm{t}_{1}\right) \text {, or, since } \\
& \mathrm{F}\left(\mathrm{t}_{1}\right)=1-\mathrm{R}\left(\mathrm{t}_{1}\right) \text {, we will have: } \\
& \mathrm{f}\left(\mathrm{t}_{1}\right)=\mathrm{n}\left[\mathrm{R}\left(\mathrm{t}_{1}\right)\right]^{\mathrm{n}-1} \mathrm{f}\left(\mathrm{t}_{1}\right)
\end{aligned}
$$

For the three-parameter Weibull sampling distribution, we will have:

$$
\mathrm{f}\left(\mathrm{t}_{1}\right)=\frac{\mathrm{n} \beta}{\theta}\left(\frac{\mathrm{t}-\varphi}{\theta}\right)^{\beta-1}\left\{\exp -\left[\left(\frac{\mathrm{t}-\varphi}{\theta}\right)^{\beta}\right]\right\}^{\mathrm{n}}
$$

The expected value of $t_{1}$ is given by

$$
\begin{aligned}
E\left(t_{1}\right)=\int_{\varphi}^{\infty} \frac{n \beta}{\theta} t & \left(\frac{t-\varphi}{\theta}\right)^{\beta-1} \times \\
& \times\left\{\exp -\left[\left(\frac{t-\varphi}{\theta}\right)^{\beta}\right]\right\}^{n} d t
\end{aligned}
$$

Making $U=\left(\frac{t-\varphi}{\theta}\right)^{\beta}$, we have:

$$
\mathrm{du}=\frac{\beta}{\theta}\left(\frac{\mathrm{t}-\varphi}{\theta}\right)^{\beta-1} \mathrm{dt}
$$

$$
\mathrm{dt}=\frac{\mathrm{du}}{\frac{\beta}{\theta}\left(\frac{\mathrm{t}-\varphi}{\theta}\right)^{\beta-1}} ; \mathrm{t}=\theta \mathrm{U}^{1 / \beta}+\varphi
$$

As $\mathrm{t} \rightarrow \infty ; \mathrm{U} \rightarrow \infty$. As $\mathrm{t} \rightarrow \varphi ; \mathrm{U} \rightarrow 0$. Then:

$$
\begin{aligned}
& E\left(t_{1}\right)=\int_{0}^{\infty} n\left(\theta U^{1 / \beta}+\varphi\right) e^{-n U} d u= \\
& =\theta \int_{0}^{\infty} n U^{1 / \beta} e^{-n U} d u+\varphi \int_{0}^{\infty} n e^{-n U} d u
\end{aligned}
$$

$$
\begin{aligned}
& \text { Here, } \varphi \int_{0}^{\infty} n e^{-n U} d u=-\varphi\left[e^{-n U}\right]_{0}^{\infty}= \\
& \quad=-\varphi[0-1]=\varphi
\end{aligned}
$$

In solving the integral

$$
\begin{aligned}
& \theta \int_{0}^{\infty} n U^{1 / \beta} e^{-n U} d u, \text { let } Z=n U \text {. Then: } \\
& d u=\frac{d z}{n} ; \quad U=\frac{Z}{n}
\end{aligned}
$$

As $U \rightarrow \infty ; Z \rightarrow \infty ;$ As $U \rightarrow 0 ; \quad Z \rightarrow 0$. Then: 


$$
\begin{aligned}
& E\left(t_{1}\right)=\theta \int_{0}^{\infty}\left(\frac{z}{n}\right)^{1 / \beta} e^{-z} d z+\varphi \\
& E\left(t_{1}\right)=\frac{\theta}{n^{1 / \beta}} \int_{0}^{\infty} z^{1 / \beta} e^{-z} d z+\varphi . \text { Finally: } \\
& E\left(t_{1}\right)=\frac{\theta}{n^{1 / \beta}} \Gamma\left(\frac{1}{\beta}+1\right)+\varphi
\end{aligned}
$$

The expected value of $t_{1}$ is given by:

$$
\mathrm{E}\left(\mathrm{t}_{1}\right)=\frac{\theta}{\mathrm{n}^{1 / \beta}} \Gamma\left(\frac{1}{\beta}+1\right)+\varphi,
$$

which indicates that $\varphi$ can be estimated at normal condition by:

$$
\mathrm{E}(\varphi)=\varphi_{\mathrm{n}}=\mathrm{t}_{1}-\frac{\theta_{\mathrm{n}}}{\mathrm{n}^{1 / \beta_{\mathrm{n}}}} \Gamma\left(\frac{1}{\beta_{\mathrm{n}}}+1\right)
$$

$\varphi$ can also be estimated at accelerated condition by:

$$
\mathrm{E}(\varphi)=\varphi_{\mathrm{a}}=\mathrm{t}_{1}-\frac{\theta_{\mathrm{a}}}{\mathrm{n}^{1 / \beta_{\mathrm{a}}}} \Gamma\left(\frac{1}{\beta_{\mathrm{a}}}+1\right)
$$

\section{EXAMPLE}

We are trying to verify if, for a threeparameter Weibull sampling distribution, a component, operating under predetermined (correct) levels of increased stress, will have exactly the same failure mechanism as observed when used at normal stress levels. In order to do so, a certain type of metallurgical part was subjected to an accelerated life test, where 15 of such parts were cycled with the testing being truncated at the moment of occurrence of the ninth failure. Table (1) below shows the failure time data (hours) obtained from the life testing under accelerated conditions:

Table 1. Failure times (hours) of metallurgical parts tested under accelerated conditions

\begin{tabular}{|l|l|l|}
\hline 26.8 & 18.0 & 57.7 \\
\hline
\end{tabular}

\begin{tabular}{|c|c|c|}
\hline 62.2 & 122.1 & 29.7 \\
\hline 94.9 & 60.7 & 90.3 \\
\hline
\end{tabular}

The underlying sampling distribution is the three-parameter Weibull model. Using the maximum likelihood estimator approach for the shape parameter $\beta$ and for the scale parameter $\theta$ of the Weibull model for censored Type II data (failure censored), we obtain the following values for these two parameters under accelerated conditions of testing.

$\beta_{\mathrm{a}}=\beta_{\mathrm{n}}=\beta=1.444 ; \theta_{\mathrm{a}}=113.1543$ hours

Now using equation (13) we obtain the estimator value for the minimum life $\varphi$ under accelerated conditions of testing:

$\varphi_{\mathrm{a}}=2.26$ hours

The Appendix (1) shows the development of the maximum likelihood estimator for censored Type II data (failure censored). A second sample is obtained at a normal stress level. Once again, 15 metallurgical parts were cycled with the testing being truncated at the moment of occurrence of the ninth failure.

Table 2. Failure times (hours) of metallurgical parts tested under normal conditions

\begin{tabular}{|c|c|c|}
\hline 415.0 & 303.3 & 177.6 \\
\hline 232.4 & 155.0 & 286.3 \\
\hline 85.4 & 180.3 & 280.0 \\
\hline
\end{tabular}

Again using the maximum likelihood estimator approach presented in Appendix 1, we obtain the following values for the shape parameter $\beta$ and for the scale parameter $\theta$ of the threeparameter Weibull sampling distribution under normal conditions of testing:

$\beta_{\mathrm{n}}=\beta_{\mathrm{a}}=\beta=1.4414 ; \theta_{\mathrm{n}}=538.3755$ hours

Using equation (12) we obtain the estimator value for the minimum life $\varphi$ under normal conditions of testing:

$\varphi_{\mathrm{n}}=10.76$ hours

Using equation (6), we will have: 
$\mathrm{AF}_{\theta}=\frac{\theta_{\mathrm{n}}}{\theta_{\mathrm{a}}}=\frac{538.3755}{113.1543}=4.7579 \approx 4.76$

Using equation (7), we will have:

$\mathrm{AF}_{\varphi}=\frac{\varphi_{\mathrm{n}}}{\varphi_{\mathrm{a}}}=\frac{10.76}{2.26}=4.7610 \approx 4.76$

Then, as we expected, $\mathrm{AF}_{\theta}=\mathrm{AF}_{\varphi}=\mathrm{AF}=$ 4.76, and $\beta_{\mathrm{n}}=\beta_{\mathrm{a}}=\beta \approx 1.44$

As we can observe in this example, under a linear acceleration assumption, the metallurgical part, operating under predetermined (correct) levels of increased stress, has exactly the same failure mechanism as observed when used at normal stress levels. That is, since the life distribution at one stress level is represented by the three-parameter Weibull model, the life distribution at any other stress level is also represented by a three-parameter Weibull model. As we can see in this example, the shape parameter value remains the same while the scale parameter and the minimum life are multiplied by the acceleration factor. As we remember, the equal shape parameter is a necessary mathematical consequence to the other two assumptions; assuming a linear acceleration model and a three-parameter Weibull sampling distribution.

\section{CONCLUSIONS}

As we are aware, the main objective of accelerated life testing models is to force components to fail by testing then at much higher than intended application conditions. The price we have to pay to go from failure rate obtained at high stress to what a product or service is likely to experience at much less stress, under use (normal) conditions, is the need for additional modeling. In this study, we developed an accelerated life-testing model in which the underlying sampling distribution is the three-parameter Weibull model. The minimum life is considered different from zero. We assumed a linear acceleration condition. As we can verify in the presented ENGEVISTA, v. 7, n. 1, p. 55-62, abril 2005 example, the shape parameter value remained the same while the scale parameter and the minimum life parameter are multiplied by the acceleration factor. As we would expect, the acceleration factor for the scale parameter $\theta$ is equal to the accelerated factor for the minimum life $\varphi$. The equal shape parameter is a necessary mathematical consequence to the other two assumptions; assuming a linear acceleration model and a three-parameter Weibull sampling distribution.

\section{REFERENCES}

[1] De Souza, Daniel I., 1999, Sequential Life Testing with an Underlying Weibull Sampling Distribution. In Safety and Reliability, Schuëller \& Kafka eds., Proceedings of the ESREL '99 International Conference on Safety and Reliability, Garching, Germany, 13-17 1999, 2:869-874, Rotterdam, Balkema.

[2] De Souza, Daniel I., 2000, Further Thoughts on a Sequential Life Testing Approach Using a Weibull Model, Foresight and Precaution, ESREL 2000 Congress, Cottam, Harvey, Pape \& Tait (eds), Edinburgh; Scotland; 14-17 May 2000; 2: 1641 - 1647, Rotterdam,: Balkema.

[3] De Souza, Daniel I., 2001, Sequential Life Testing with a Truncation Mechanism for an Underlying Weibull Model, Towards a Safer World, ESREL 2001 Conference, Zio, Demichela \& Piccinini (eds), Torino, Italy, $16-20$ September 2001; 3: 1539 - 1546, Politecnico Di Torino.

[4] De Souza, Daniel I., 2002, The Bayesian Approach to Sequential Testing with an Underlying Weibull Model, European Conference on System Dependability and Safety, ESREL 2002 Conference, Lyon, France, 18 - 21 March 2002; 2: $617-621, \lambda \mu 13$ (eds).

[5] De Souza, Daniel I. 2003. Sequential Life Testing with a Truncation Mechanism for an Underlying ThreeParameter Weibull Model, Icheap-6, Chemical Engineering Transactions, Vol. 3 p. 557-562, Sauro Pierucci (ed), Pisa, Italy. 
[6] De Souza, Daniel I. 2004a. Application of a Sequential Life Testing with a Truncation Mechanism for an Underlying Three-Parameter Weibull Model. ESREL 2004 - PSAM 7 Conference, Spitzer, Schmoker and Dang (eds.), Berlin, Germany, 14 - 18 June 2004, Vol. 3; pp. 1674-1680, SpringerVerlag publishers.

[7] De Souza, Daniel I. (1999) Accelerated Life Testing Models. In: ORSNZ99 Conference,1999, Hamilton. Proceedings of the ORSNZ99 Conference. Hamilton: University of Waikato, NZ, 1999. v.1, p. 245-254.

[8] De Souza, Daniel I. (1999). Physical Acceleration Life Models. In: XIII Congreso Chileno de Ingenieria Electrica, 1999, Santiago. Anais del XIII Congreso Chileno de Ingenieria Electrica. Santiago: Universidad de Santiago de Chile, 1999. v.1, p. 09-14.

[9] Erto, P. (1982). New Practical Bayes Estimators for the 2-Parameter Weibull Distribution. IEEE Transactions on Reliability, Vol. R-31, No 2, June, pp. 194-197.

[10] Mann, N.R. (1968). Point and Interval Estimation Procedure Procedures for the Two-Parameter Weibull and Extreme-Value Distributions, Technometrics, Vol. 10, No 2, May, pp. 231-256.

[11] Papadopoulos, A.S. and Tsokos, C.P. (1975), Bayesian Confidence Bounds for the Weibull Failure Model. IEEE Transactions on Reliability, Vol. R24, No 1, April, pp.21-26.

[12] Soland, R.M. (1969). Bayesian Analysis of the Weibull Process with Unknown Scale and Shape Parameters. IEEE Transactions on Reliability, Vol. R18, No 4, November, pp. 181-184.

[13] Tate, R.F. (1959). Unbiased Estimation Functions of Location and Scale parameters. Ann. Math. Statistics, 30, pp. 341-366.

\section{APPENDIX 1. MAXIMUM LIKELIHOOD ESTIMATION FOR THE WEIBULL MODEL FOR CENSORED TYPE II DATA (FAILURE CENSORED)}

The maximum likelihood estimator for the shape and scale parameters of a Weibull sampling distribution for censored Type II data (failure censored) will be given by:

$$
\begin{aligned}
& \mathrm{L}(\beta ; \theta)=\mathrm{k} !\left[\prod_{i=1}^{\mathrm{r}} \mathrm{f}\left(\mathrm{t}_{\mathrm{i}}\right)\right]\left[1-\mathrm{F}\left(\mathrm{t}_{\mathrm{r}}\right)\right]^{\mathrm{n}-\mathrm{r}}= \\
& \mathrm{L}(\beta ; \theta)=\mathrm{k} !\left[\prod_{i=1}^{\mathrm{r}} \mathrm{f}\left(\mathrm{t}_{\mathrm{i}}\right)\right]\left[\mathrm{R}\left(\mathrm{t}_{\mathrm{r}}\right)\right]^{\mathrm{n}-\mathrm{r}} ; \mathrm{t}>0
\end{aligned}
$$

With $\mathrm{f}\left(\mathrm{t}_{\mathrm{i}}\right)=\frac{\beta}{{ }_{\theta}^{\beta}}\left(\mathrm{t}_{\mathrm{i}}\right)^{\beta-1} \mathrm{e}^{-\left(\mathrm{t}_{\mathrm{i}} / \theta\right)^{\beta}}$ and $\mathrm{R}\left(\mathrm{t}_{\mathrm{r}}\right)=\mathrm{e}^{-\left(\mathrm{t}_{\mathrm{r}} / \theta\right)^{\beta}}$, we will have

$$
\begin{aligned}
L(\beta ; \theta)= & k ! \frac{\beta^{r}}{\theta^{\beta r}}\left[\prod_{i=1}^{r} t_{i}\right]^{\beta-1} \times \\
& \times e^{-\sum_{i=1}^{r}\left(t_{i} / \theta\right)^{\beta}}\left[e^{-\left(t_{r} / \theta\right)^{\beta}}\right]^{n-r}
\end{aligned}
$$

The log likelihood function will be given by:

$$
\begin{aligned}
& \mathrm{L}=\ln [\mathrm{L}(\beta ; \theta)]=\ln (\mathrm{k})+\mathrm{r} \ln (\beta)-\mathrm{r} \beta \ln (\theta)+ \\
& +(\beta-1) \sum_{\mathrm{i}=1}^{\mathrm{r}} \ln \left(\mathrm{t}_{\mathrm{i}}\right)-\sum_{\mathrm{i}=1}^{\mathrm{r}}\left(\frac{\mathrm{t}_{\mathrm{i}}}{\theta}\right)^{\beta}-(\mathrm{n}-\mathrm{r}) \times \\
& \times\left(\frac{\mathrm{t}_{\mathrm{r}}}{\theta}\right)^{\beta}
\end{aligned}
$$

To find the value of $\theta$ and $\beta$ that maximizes the log likelihood function, we take the $\theta$ and $\beta$ derivatives and make them equal to zero. Then, we will have:

$$
\begin{aligned}
\frac{\mathrm{dL}}{\mathrm{d} \theta}=-\frac{\mathrm{r} \beta}{\theta} & +\frac{\beta \times \sum_{\mathrm{i}=1}^{\mathrm{r}}\left(\mathrm{t}_{\mathrm{i}}\right)^{\beta}}{\theta^{\beta+1}}+ \\
& +\frac{\beta(\mathrm{n}-\mathrm{r})\left(\mathrm{t}_{\mathrm{r}}\right)^{\beta}}{\theta^{\beta+1}}=0
\end{aligned}
$$




$$
\begin{aligned}
& \frac{\mathrm{dL}}{\mathrm{d} \beta}=\frac{\mathrm{r}}{\beta}-\mathrm{r} \ln (\theta)+\sum_{\mathrm{i}=1}^{\mathrm{r}} \ln \left(\mathrm{t}_{\mathrm{i}}\right)- \\
&-\sum_{\mathrm{i}=1}^{\mathrm{r}}\left(\frac{\mathrm{t}_{\mathrm{i}}}{\theta}\right)^{\beta} \ln \left(\frac{\mathrm{t}_{\mathrm{i}}}{\theta}\right)-(\mathrm{n}-\mathrm{r})\left(\frac{\mathrm{t}_{\mathrm{r}}}{\theta}\right)^{\beta} \times \\
& \times \ln \left(\frac{\mathrm{t}_{\mathrm{r}}}{\theta}\right)=0
\end{aligned}
$$

From equation (A) we obtain:

$$
\theta=\left(\frac{\sum_{i=1}^{r}\left(t_{i}\right)^{\beta}+(n-r)\left(t_{r}\right)^{\beta}}{r}\right)^{1 / \beta}
$$

Notice that, when $\beta=1$, equation (C) reduces to the maximum likelihood estimator for the exponential distribution. Using equation (C) for $\theta$ in equation (B) and applying some algebra, equation (B) reduces to:

$$
\begin{aligned}
& \frac{\mathrm{r}}{\beta}+\sum_{\mathrm{i}=1}^{\mathrm{r}} \ln \left(\mathrm{t}_{\mathrm{i}}\right)- \\
& -\underline{r \times\left[\sum_{i=1}^{r}\left(t_{i}\right)^{\beta} \ln \left(t_{i}\right)+(n-r)\left(t_{r}\right)^{\beta} \ln \left(t_{r}\right)\right]}= \\
& \sum_{i=1}^{r}\left(t_{i}\right)^{\beta}+(n-r)\left(t_{r}\right)^{\beta} \\
& =0 \quad \text { (D) }
\end{aligned}
$$

Equation (D) must be solved iteratively. 